\title{
Dietary diversity practice and associated factors among pregnant women attending ANC in Kolfe Keranyo sub city health center, Addis Ababa, Ethiopia.
}

\section{Tsegahun Worku Brhanie ( $\nabla$ w.tsegaw@yahoo.com )}

Bahir Dar University

\section{Walelgn Tefera}

Kementerian Kesehatan Republik Indonesia Badan Penelitian dan Pengembangan Kesehatan

\section{Mamo Dereje}

Ministry of Health

\section{Research article}

Keywords: Pregnant women, dietary diversity, Dietary Diversity Score, antenatal care, Ethiopia.

Posted Date: June 24th, 2020

DOI: https://doi.org/10.21203/rs.3.rs-33570/v1

License: (c) (i) This work is licensed under a Creative Commons Attribution 4.0 International License.

Read Full License 


\section{Abstract}

Background: Adequate and healthy diet during pregnancy is essential for the health of both mother and newborn. Dietary diversity is a proxy indicator of maternal nutrient adequacy. However, little is documented on the prevalence of dietary diversity among pregnant women.

This study was aimed to assess the dietary diversity practice and associated factors among pregnant women attending antenatal care in health centers of the coffee keranyo sub city, Addis Ababa, Ethiopia.

Methods: Institution based cross-sectional study was conducted on 406 randomly selected pregnant women attending ANC in health centers of the coffee keranyo sub city, Addis Ababa from March 2-April $2 / 2018$. Data were collected by using interviewer and $24 \mathrm{H}$ dietary recall method. Data had entered and analyzed using SPSS version 21. Multiple logistic regression was run to assess factors associated with the dependent variable at $\mathrm{P}<0.05$.

Results: The mean Dietary Diversity Score of pregnant women was 5. 45+-1. 83. About $60.9 \%$ of pregnant women had good dietary diversity practice. Pregnant women who learned collage and above had more dietary diversity practice than the illiterate one [AOR=2.26, 95\% Cl: $(1.066,4.808)]$. Pregnant women with monthly income more than 5,000 ETB had more dietary diversity than income less than 2,000 ETB [AOR=2.33, 95\% Cl: $(1.234,4.416)]$. Pregnant women at second antenatal care visit had more dietary diversity than at the first visit [AOR=2.42, 95\% Cl: $(1.183,4.952)]$. Having nutrition information during pregnancy increases 2 times better dietary diversity practice than none informed ones [AOR=2.10, 95\% Cl: $(1.294,3.422)]$.

Conclusions: The mean Dietary Diversity Score of pregnant mothers was 5.45 . And $60.9 \%$ of pregnant women had a good dietary diversity score, whereas $39.1 \%$ of them had a poor diet diversity score. Mothers' education, monthly income, second and third antenatal care visit and nutrition information had a significantly associated with pregnant mothers' dietary diversity.

\section{Background}

Adequate and healthy diet during pregnancy is essential for the health of both mother and newborn. Dietary diversity is a proxy indicator of maternal nutrient adequacy.

Dietary diversity refers to an increase in the variety of foods across and within food groups capable of ensuring adequate intake of essential nutrients that can promote good health, and physical and mental development (1).

There is no any single food which contains all the required nutrients for optimal health. (2) And a diversified diet is associated with a good nutritional status (3). A variety of foods in the diet has therefore been considered important in ensuring adequate intake of essential nutrients and in realizing an optimal nutritional status (4). Dietary diversity has been shown to be strongly and positively correlated with 
nutrient adequacy in low-income countries. Nutrient adequacy is one important element of diet quality. Thus, the Minimum Dietary Diversity of Women can be used as a proxy for this aspect of diet quality. It can be used to monitor and evaluate programs that seek to improve diet quality in resource-constrained settings (5). Lack of dietary diversity is a challenge for communities in developing countries. Their diets are by default defined on starchy staples with inadequate animal products, fresh fruits and vegetables (6).

During pregnancy a woman needs good nutritional status for a healthy outcome. Women who have a poor nutritional status at conception are at higher risk of disease and death; their health depends greatly on the availability of food, and they may be unable to cope with their increased nutrient needs during pregnancy in situations of food insecurity. Infections such as malaria, HIV and infestation with gastrointestinal parasites can exacerbate such women's under nutrition (7).

During pregnancy all women need more food, a varied diet, and micronutrient supplements. When energy and other nutrient intake do not increase, the body's own reserves are used, leaving a pregnant woman weakened. Energy needs increase in the second and particularly the third trimester of pregnancy. Inadequate weight gain during pregnancy often results in low birth weight, which increases an infant's risk of dying Pregnant women also require more protein, iron, iodine, vitamin A, folate, and other nutrients. Deficiencies of certain nutrients are associated with maternal complications and death, fetal and newborn death, birth defects, and decreased physical and mental potential of the child. Pregnant women need to consume extra vitamins and minerals, increase their calorie intake, and avoid certain foods such as chemicals to optimize the growth and development of their baby (8). However, little is documented on the importance of dietary diversity among pregnant women.

This study aimed to assess the dietary diversity practice and associated factors among pregnant women attending antenatal care in health centers of the coffee keranyo sub city, Addis Ababa, Ethiopia.

\section{Methods}

\subsection{Description of the study area}

The study was conducted in the Kolfe Keranyo sub city which is one of the ten sub city of Addis Ababa. Addis Ababa is the capital city of Ethiopia and represented by all ethnic groups of Ethiopia. Administratively, the city is divided into 10 sub cities and 116 districts. The city has 3.8 million populations and has health service access in less than 2 kilometers for all people. There are 5 hospitals under the Ministry of heath, 6 Hospitals under Addis Ababa Health Bureau, 2 Hospitals under Ministry of Defense, 1 Hospital under Police Force and around 40 Private Hospitals. The city also has 95 functional governmental health centers and more than 760 private clinics in the 10 sub cities. The cafe Keranyo sub city is found in the western part of Addis Ababa, Ethiopia. Administratively, the sub city is divided into 15 districts. There are 1 hospital under Ministry of health and 3 Private Hospitals. The sub city also has 11 functional novernmental health renters and more than 176 private clinics in the sub cities (38). Based on Loading [MathJax]/jax/output/CommonHTML/fonts/TeX/fontdata.js 
Kolfe Keranyo sub city health office, the total population of the sub city in 2017 is estimated to be around 547,940 and has a growth rate of $3.8 \%$ and population density of 4,165 persons per square kilometer. The sex ratio shows $48.5 \%$ are males and $51.5 \%$ are females. It had an estimated number of pregnancy 12 , 603 (38).

\subsection{Study Design}

Institutional based cross-sectional design was employed to assess dietary diversity among pregnant women attending ANC in public health centers of Kolfe Keranyo sub city, Addis Ababa.

\subsection{Source and Target Population}

\subsubsection{Source population}

The source populations were all pregnant women attending ANC in public health centers of Kolfe Keranyo sub city.

\subsubsection{Target Population}

All Pregnant women who visit the randomly selected health facilities during March to April, 2018 were considered as the study population

\subsection{Inclusion and exclusion criteria}

\subsubsection{Inclusion criteria}

All pregnant women attending ANC in the study facilities and being a resident of Kolfe Keranyo sub city for at least 6 months were included.

\subsubsection{Exclusion criteria}

All pregnant women attending ANC in the study facilities and currently live out of Kolfe Keranyo sub city were excluded.

\subsection{Study Variables}

\section{Dependent Variable}

Dietary diversity practice of pregnant women with

\section{Independent Variables}

age, educational status, health status, religion, occupation, number of ANC visit, nutrition information, parity, trimester, family size, Income level and food item avoidance.

\subsection{Operational Definitions}


Refers to the number of food groups consumed by pregnant women over a 24-hour period.

\section{Low or poor dietary diversity score}

When pregnant women consumed less than five food groups among the 10 groups within $24 \mathrm{~h}$ before the survey.

\section{High or good dietary diversity score}

When pregnant women consumed five or more food groups among the 10 groups within $24 \mathrm{~h}$ before the survey.

\section{Minimum Dietary Diversity of pregnant women}

Dietary diversity score of pregnant women receiving at least five food groups out of ten.

\section{Dietary adequacy}

taking any amount of each food group is considered as adequate.

\section{Poor household}

households with monthly income less than 2,000 ETB.

\section{Medium household}

households with monthly income from 2,000-5,000 ETB

Rich household; households with monthly income more than 5,000 ETB

\subsection{Sample Size Determination}

The required sample size was determined using the following assumption

\section{Assumption 1}

Of the proportion of dietary diversity practice, based on the previous study in Gondar, the prevalence of dietary practice is up $=40.1 \%(21)$.

Where: $\mathrm{n}=$ required sample sizes, $10 \%=$ non - respondent wrote

$\mathrm{Za} / 2=$ critical value for normal distribution at $95 \%$ confidence interval which equals to 1.96 (Z value at alpha $=0.05), d=$ an absolute precision (margin of error) $=5 \%$

For the first objective: 
$\mathrm{n} 1=(\mathrm{za} / 2)^{2} \mathrm{p}(1-\mathrm{p}) / \mathrm{d}^{2}=\left(1.9^{2} \times 0.6 \times 0.4\right) / 0.05 \square=0.921984 / 0.0025=368.79=369$

Dietary diversity practice $(\mathrm{P} 1=40.1 \%) \mathrm{n} 1=369$

Adding non-response rate of $10 \%=(369+369 \times 10 \%)=406$

\section{For the second objective:}

The sample size required was calculated using two-population proportion formula by assuming; $r=$ $n 2 / n 1=1: 1, \mathrm{Z}$ a/2 = the value of the standard normal distribution curve corresponding to the level of significance alpha $0.05=1.96$ and the value of the standard normal distribution curve corresponding to $90 \%$ power $=1.21$

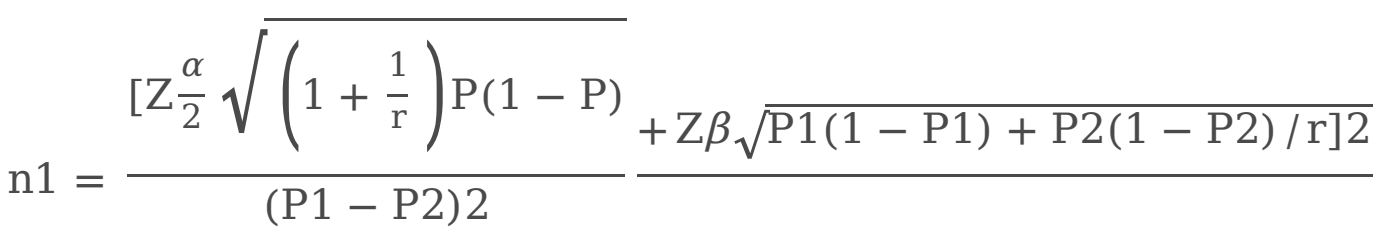

Where: $P=\left(P_{1}+r P_{2}\right.$

$1+r$

for household income p1 = Prevalence of DDS at household income $<1000$ birr $=25.8 \%, p 2=$ Prevalence of DDS at household income $1000-2000=51.3 \%$.for educational status $\mathrm{p} 1=$ Prevalence of DDS among illiterate mothers $=23.5 \%, \mathrm{p} 2=$ Prevalence of DDS among mothers learn college and above $=52.5 \%$; for nutrition information $\mathrm{p} 1=$ Prevalence of DDS among mothers who had not nutrition information $=20.6 \%$, p2 $=$ Prevalence of DDS among mothers who had nutrition information $=45.5 \%$;for marital status $\mathrm{p} 1=$ Prevalence of DDS among unmarried $=60 \%, p 2=$ Prevalence of DDS among married mothers $=40 \%$. 
Table 1

sampling size determination of associated factors of dietary diversity practice of pregnant women Kolfe Keranyo sub city, Addis Ababa, 2018.

\begin{tabular}{|c|c|c|c|c|c|c|c|c|}
\hline Variables & $\begin{array}{l}\text { DDS } \\
\text { P1 } \\
(\%)\end{array}$ & $\begin{array}{l}\text { DDS } \\
\text { P2 } \\
(\%)\end{array}$ & $\mathrm{Cl}$ & Power & $\begin{array}{l}\text { Allocation } \\
\text { ratio }\end{array}$ & OR & $\begin{array}{l}\text { Total } \\
\text { sample } \\
\text { size }\end{array}$ & Reference \\
\hline Monthly income & $25.8 \%$ & $51.3 \%$ & $95 \%$ & $90 \%$ & $1: 1$ & 2.59 & 163 & \multirow{3}{*}{$\begin{array}{l}\text { Mekonnen } \\
\text { Sisay. } \\
\text { et al,2014 }\end{array}$} \\
\hline Education status & $23.5 \%$ & $52.5 \%$ & $95 \%$ & $90 \%$ & $1: 1$ & 2.18 & 121 & \\
\hline $\begin{array}{l}\text { Nutrition } \\
\text { information }\end{array}$ & $20.6 \%$ & $45.5 \%$ & $95 \%$ & $90 \%$ & $1: 1$ & 2.39 & 154 & \\
\hline Marital status & $60 \%$ & $40 \%$ & $95 \%$ & $90 \%$ & $1: 1$ & 2.62 & 272 & $\begin{array}{l}\text { Direslgne } \\
\text { Miskir. } \\
\text { et al,2016 }\end{array}$ \\
\hline
\end{tabular}

Therefore, the sample size was 406 among pregnant mothers who attending antenatal care.

\subsection{Sampling Procedure}

A simple random sampling technique was employed to select health centers in the study area. From 11 health centers of sub cities 4 health centers were selected randomly. Then all pregnant women who visit the health center were recorded as a sampling frame in the selected health centers.

Finally, the sample size was proportionally allocated to selected health center catchment population and estimated pregnancy of Kolfe Keranyo sub city. Respondents were chosen with a systematic random sampling technique with every 2 nd pregnant women based on the time of visiting. Kolfe Keranyo sub city has 11 functional health centers namely;- woreda1 (Ayer tena), woreda3(kara), woreda4 (AlemBank), woreda5 (Zenebework) ,woreda6( Woira), woreda8 (keranyo),woreda9 (total),woreda11 (philipos),woreda12 ( kolfe), woreda13 (lomi meda), and woreda 14 (Birchiko).

Catchment population of the sub city has been estimated at 547,940 and estimated pregnancy of 12,603 (38

\subsection{Data Collection Tool and Procedure}

Data had collected from exit interview using a structured questionnaire and 24 hour recalls method adapted from different literatures mainly Food and Agriculture Organization (FAO) Guidelines for measuring household and individual dietary diversity (FAO, 2016) and (Exploring the new indicator Minimum Dietary Diversity-Women Results from Burkina Faso, 2015). A total of ten food groups was considered in this study, i.e. Cereals (Grains, white roots and tubers, and plantain), Pulses (beans, peas and lentils), Nuts and seeds, Dairy products, Meat, Poultry, and Fish, Eggs, Dark green leafy vegetables, 
The questionnaire had four main contents: The first includes socio demographic variables of pregnant women, including age, educational status, Religion, occupation, No of pregnancy or parity and trimester. The second group encompasses characteristics of the household, includes family size and household Income level, the third group captured Antenatal care, Health status and nutrition information. The fourth group includes: 24 hour recall feeding practice and dietary diversity. The questionnaire was first prepared in English and then translated to Amharic and translated back to English to observe its consistency. Dietary diversity score (DDS) was collected and calculated as the sum of the number of different food groups consumed by the pregnant women in the $24 \mathrm{H}$ prior to the assessment.

\subsection{Data quality management}

Four clinical nurses were participated in the data collection process. The data collection process was supervised by two senior Public Health professionals and the principal investigators. Both data collectors and supervisors were trained for 1 day about the contents of the questionnaire and on how to collect the data properly in order to minimize errors. The principal investigators and supervisors had made daily supervision during the whole data collection process. The questionnaire was reviewed and checked for completeness, accuracy and consistency by the supervisors and investigators daily and at the end of the whole data collection process.

The questionnaires were pre-tested to check on the length, content, question wording and language. The questionnaire was administered to $5 \%$ the sample size, who had attended ANC at non selected (Alem bank) health center. Then error was corrected accordingly.

\subsection{Data analysis}

After all the relevant data was collected, it had entered and then analyzed using SPSS version 21.Using the 10 food groups, dietary diversity categories were formulated namely; low dietary diversity category (< 5 food groups) and good or high dietary diversity category ( $\geq 5$ food groups). The dietary diversity score variable was dichotomized as category 0 for those not meeting the minimum dietary diversity and category 1 for those meeting the minimum diversity.

In the bivariate analysis, the independent variables with a P-value less than 0.05 with the dependent variable were fitted into a multivariable logistic regression model to identify their independent effect on dietary diversity. Independent variables included in the multivariable analysis include mother's educational status, trimester, and number of ANC visit, nutrition information and household monthly income. The association between the dependent and the independent variables was measured using odds ratio (OR) with $95 \%$ Confidence Interval $(\mathrm{Cl})$. Those variables with p-value of less than 0.05 in the multivariable analysis were considered to be significant for predictors of minimum dietary diversity.

\section{Result}




\subsection{Socio- demographic characteristics}

Of the 406 eligible respondents, 402 were willing to respond the questionnaire, which was a response rate of $99 \%$. The mean age of the pregnant women was $27.35 \pm 7.89$ SD with the range of $16-44$ years. Most of the women were married (91.5\%) and only $26.1 \%$ of the respondents learn collage and above and $30.1 \%$ of the pregnant women were housewife.

$78.4 \% \%$ pregnant women were not the household heads, about $81(20.2 \%)$ of the pregnant women are informal salaried employees.

In regard to family size, the average size was 4 people, with $4.47 \pm 1.95$ SD. The mean monthly household income was 3686.26 ETB and about 306 (76.1\%) of the household earned below 5000 ETB monthly. 
Table 2

Socioeconomic and Demographic characteristics of Pregnant Women in Kolfe Keranyo sub city, Addis Ababa 2018. ( $n=402)$

\begin{tabular}{|c|c|c|}
\hline Variables & Frequency & Percentage \% \\
\hline Age $<20$ & 79 & 19.7 \\
\hline $20-29$ & 176 & 43.7 \\
\hline$\geq 30$ & 147 & 36.6 \\
\hline \multicolumn{3}{|l|}{ Mean $27.35 \pm 7.9$ SD } \\
\hline Religion Orthodox & 179 & 44.5 \\
\hline Muslim & 150 & 37.3 \\
\hline Protestant & 59 & 14.7 \\
\hline Catholic & 14 & 3.5 \\
\hline Marital status Married & 368 & 91.5 \\
\hline Unmarried & 22 & 5.5 \\
\hline Divorced & 12 & 3.0 \\
\hline Education Illiterate & 52 & 12.9 \\
\hline Primary & 119 & 29.6 \\
\hline Secondary & 126 & 31.3 \\
\hline Tertiary & 105 & 26.1 \\
\hline Occupation Salaried & 81 & 20.2 \\
\hline Labour & 74 & 18.4 \\
\hline Business & 84 & 20.9 \\
\hline Housewife & 122 & 30.3 \\
\hline Other & 41 & 10.2 \\
\hline Household head Respondent & 87 & 21.6 \\
\hline Husband & 315 & 78.4 \\
\hline Level of income $<2,000$ & 95 & 23.6 \\
\hline $2,000-3,500$ & 113 & 28.1 \\
\hline $3,501-5,000$ & 98 & 24.4 \\
\hline$>5,000$ & 96 & 23.9 \\
\hline
\end{tabular}

Page $10 / 21$ 


\begin{tabular}{|llll|}
\cline { 2 - 3 } & Variables & Frequency & Percentage \% \\
\hline Family size 1-3 & 169 & 42.0 \\
$4-6$ & 150 & 37.3 \\
$>=7$ & 83 & 20.7 \\
Mean 4.47 \pm 1.95 SD & & \\
\hline
\end{tabular}

\subsection{Maternal and nutrition characteristics}

The mean parity of the study respondents was 3 children with the range $1-7$. More than half $(51.2 \%)$ of the pregnant women were in their second trimester and about $165(41.0 \%)$ of the respondents were at second ANC visit during the interview. About 190 (47.3\%) of having nutrition information about the importance of dietary diversity during pregnancy, And the ANC visit was the main source of information for $63 \%$ of mothers.

Notably, in regard to maternal morbidity, the study found that $117(29.1 \%)$ of the pregnant women reported some form of illness/disorder in the preceding two weeks prior to the day of the interview. The most commonly reported disorders were dyspepsia/heartburn by $37 \%$ of the study participants. Due to cultural or personal dislike 126 (31.3\%) of pregnant women had avoided at least one food item from their meal. Of these egg $46 \%$, dark green leafy vegetables $27 \%$ and milk and milk products $17 \%$. 
Table 3

Maternal and nutrition characteristics of pregnant women in Kolfe Keranyo sub city, Addis Ababa 2018. $(n=402)$

\begin{tabular}{|c|c|c|}
\hline Variables & Frequency & $\begin{array}{l}\text { Percentage } \\
\%\end{array}$ \\
\hline No of parity $1-3$ & 268 & 66.7 \\
\hline $4-6$ & 123 & 30.6 \\
\hline$>=7$ & 11 & 2.7 \\
\hline \multicolumn{3}{|l|}{ Mean $2.95 \pm 1.69$ SD } \\
\hline Trimester 1 st Trimester & 39 & 9.7 \\
\hline 2nd Trimester & 206 & 51.2 \\
\hline 3rd Trimester & 157 & 39.1 \\
\hline Time of ANC started 1st trimester & 161 & 40.0 \\
\hline 2nd trimester & 231 & 57.5 \\
\hline 3rd trimester & 10 & 2.5 \\
\hline No of ANC visit 1st visit & 88 & 21.9 \\
\hline 2nd visit & 165 & 41.0 \\
\hline 3rd visit & 106 & 26.4 \\
\hline 4th and above visit & 43 & 10.7 \\
\hline Have you been sick in the last 2 weeks? Yes & 117 & 29.1 \\
\hline No & 285 & 70.9 \\
\hline \multirow{2}{*}{$\begin{array}{l}\text { Do you have an information about dietary diversity is important during } \\
\text { pregnancy? Yes }\end{array}$} & 190 & 47.3 \\
\hline & 212 & 52.7 \\
\hline Do you avoid any food group in the current pregnancy? Yes & 126 & 31.3 \\
\hline No & 276 & 68.7 \\
\hline
\end{tabular}

\subsection{4 hours dietary diversity practices of pregnant mothers 5.3.1 Dietary diversity score of the pregnant women}

Out of the 10 food groups, the study found the mean DDS was $5.45 \pm 1.83$ SD with scores ranging from 3 to10 food groups. Based on the categories developed, Nearly 2/3rd (60.9\%) of respondents had a good dietary diversity score ( $\geq 5$ food groups) and about $39.1 \%$ of the participants were in the low diversity 
The most commonly eaten foods were cereals $(100 \%)$ and pulses were the second most eaten food group $63.9 \%$. Notably, the egg was minimally consumed 36 (8.9\%).

Table 4

Respondents by food group, pregnant women in kolfe keranyo sub city, Addis Ababa 2018. $(\mathrm{N}=402)$

\begin{tabular}{|lll|}
\hline Food group & $\mathbf{N = 4 0 2}$ & Percentage \\
\hline Cereals (Grains, white roots and tubers, and plantain) & 402 & 100 \\
\hline Pulses (beans, peas and lentils) & 257 & 63.9 \\
\hline Nuts and seeds & 132 & 32.8 \\
\hline Dairy products & 149 & 37.0 \\
\hline Meat, poultry, and fish & 189 & 47.0 \\
\hline Eggs & 36 & 8.9 \\
\hline Dark green leafy vegetables & 173 & 43.0 \\
\hline Other vitamin A-rich fruits and vegetables & 129 & 32.0 \\
\hline Another vegetable & 253 & 62.9 \\
\hline Other fruits & 88 & 21.8 \\
\hline
\end{tabular}

\subsection{Factors associated with dietary diversity practice of pregnant women}

Bivariate analysis showed that there was an association between dietary diversity practices of pregnant mothers and mother's educational status, trimester, number of ANC visit, nutrition information and household monthly income, whereas, age, marital status, religion, household head, mothers occupation, parity, family size, time of ANC start, avoidance of food items and sickness had no association with dietary diversity practices of mothers.

The result Table 5 of, multivariate analysis showed that there was statistically significant $(p<0.05)$ association between educational status, family monthly income, number of ANC visit and nutrition information dietary diversity practices of pregnant mothers.

Pregnant women learned collage and above had 2.3 times, good dietary diversity practice than the illiterate mothers [AOR $=2.264 ., 95 \% \mathrm{Cl}:(1.066,4.808)]$. Pregnant women with household income more than 5,000 ETB had dietary diversity practice almost 2.3 times than those households having a household income less than 2000 per month [AOR $=2.334,95 \% \mathrm{Cl}:(1.234,4.416)]$. Pregnant women who were at second ANC visit had 2.4 times more attaining minimum dietary diversity than who were at the first visit $[A O R=2.420,95 \% \mathrm{Cl}:(1.183,4.952)]$. 
There was also a statistical association between nutrition information and minimum dietary diversity practices of mothers during pregnancy. Having nutrition information during pregnancy increases 2 times the dietary diversity practice of pregnant women than none informed ones [AOR $=2.104,95 \% \mathrm{Cl}$ : $(1.294$, 3.422)]. 
Table 5

; Multivariable logistic regression analyses showed factors associated with dietary diversity practice among pregnant women in Kolfe Keranyo sub city, Addis Ababa 2018. $(n=402)$

\begin{tabular}{|c|c|c|c|c|c|}
\hline \multirow[t]{2}{*}{ Variables } & \multicolumn{2}{|l|}{ Practice } & \multirow[t]{2}{*}{ COR with $95 \% \mathrm{Cl}$} & \multirow{2}{*}{$\begin{array}{l}P \\
\text { value }\end{array}$} & \multirow{2}{*}{$\begin{array}{l}\text { AOR with } \\
95 \% \mathrm{Cl}\end{array}$} \\
\hline & $\underset{\text { (High) }}{\geq 5}$ & $\begin{array}{l}<5 \\
\text { (Low) }\end{array}$ & & & \\
\hline \multirow{5}{*}{$\begin{array}{l}\text { Education Illiterate } \\
\text { Primary } \\
\text { Secondary } \\
\text { Collage and above }\end{array}$} & $22(5.5)$ & $30(7.5)$ & 1.00 & 0.033 & 1.00 \\
\hline & \multirow{3}{*}{$\begin{array}{l}72(17.9) \\
79 \\
(19.7)\end{array}$} & \multirow{2}{*}{$\begin{array}{l}47 \\
(11.7)\end{array}$} & $2.09(1.08,4.05)$ & 0.034 & $\begin{array}{l}2.16(1.06- \\
4.39)\end{array}$ \\
\hline & & & \multirow{3}{*}{$\begin{array}{l}2.29(1.19,4.43) \\
2.98(1.50,5.92)\end{array}$} & \multirow[t]{3}{*}{0.033} & \\
\hline & & (11.7) & & & $4.30)$ \\
\hline & $\begin{array}{l}72 \\
(17.9)\end{array}$ & $33(8.2)$ & & & $\begin{array}{l}2.26(1.07- \\
4.81)\end{array}$ \\
\hline \multirow{6}{*}{$\begin{array}{l}\text { Income }<2000 \\
2000-3500 \\
3501-5000 \\
>5000\end{array}$} & $\begin{array}{l}45 \\
(11.2)\end{array}$ & \multirow{2}{*}{$\begin{array}{l}50 \\
(12.4)\end{array}$} & \multirow{2}{*}{$\begin{array}{l}1.002 .108 \\
(1.2053 .688)\end{array}$} & \multirow{2}{*}{$\begin{array}{l}0.056 \\
0.208\end{array}$} & 1.00 \\
\hline & \multirow{2}{*}{$\begin{array}{l}74 \\
(18.4)\end{array}$} & & & & $1.78(0.98-$ \\
\hline & & \multirow{2}{*}{$\begin{array}{l}39(9.7) \\
39(9.7)\end{array}$} & & \multirow[t]{2}{*}{0.009} & $3 . Z Z)$ \\
\hline & 59 & & \multirow{3}{*}{$\begin{array}{l}2.567(1.418- \\
4.646)\end{array}$} & & $2.75)$ \\
\hline & & & & & $2.33(1.23-$ \\
\hline & $\begin{array}{l}67 \\
(16.7)\end{array}$ & & & & 4.42) \\
\hline \multirow{4}{*}{$\begin{array}{l}\text { Trimester } \\
\text { 1st trimester } \\
\text { 2nd trimester } \\
\text { 3rd trimester }\end{array}$} & $19(4.7)$ & $20(5)$ & \multirow{4}{*}{$\begin{array}{l}1.00 \\
1.25(0.63,2.49) \\
2.79(1.36,5.73)\end{array}$} & 0.201 & 1.00 \\
\hline & \multirow{2}{*}{$\begin{array}{l}112 \\
(27.9)\end{array}$} & \multirow{2}{*}{$\begin{array}{l}94 \\
(23.4)\end{array}$} & & \multirow[t]{3}{*}{0.674} & $0.56(0.23-$ \\
\hline & & & & & \\
\hline & $(28.4)$ & $\begin{array}{l}43 \\
(10.7)\end{array}$ & & & $2.23)$ \\
\hline \multirow{2}{*}{$\begin{array}{l}\text { Number of ANC attendance } \\
1 \text { st visit }\end{array}$} & $35(8.7)$ & \multirow{2}{*}{$\begin{array}{l}53 \\
(13.2)\end{array}$} & 1.00 & 0.016 & 1.00 \\
\hline & \multirow{2}{*}{$\begin{array}{l}104 \\
(25.9)\end{array}$} & & \multirow{2}{*}{$\begin{array}{l}2.58(1.52,4.39) \\
3.35(1.85,6.06)\end{array}$} & \multirow{3}{*}{$\begin{array}{l}0.046 \\
0.058\end{array}$} & $2.42(1.18-$ \\
\hline 2nd visit & & $(15.2)$ & & & \\
\hline 3rd visit & $\begin{array}{l}73 \\
(18.2)\end{array}$ & $33(8.2)$ & $4.99(2.19,11.42)$ & & $\begin{array}{l}2.30(1.01- \\
5.21)\end{array}$ \\
\hline 4th and above & $33(8.2)$ & $10(2.5)$ & & & $\begin{array}{l}2.87(0.96- \\
8.51)\end{array}$ \\
\hline $\begin{array}{l}\text { Having nutrition information } \\
\text { Yes }\end{array}$ & $\begin{array}{l}142 \\
(35.3)\end{array}$ & $\begin{array}{l}48 \\
(11.9)\end{array}$ & $3.13(2.05,4.78)$ & 0.003 & $\begin{array}{l}2.10(1.29- \\
3.42)\end{array}$ \\
\hline No & $\begin{array}{l}103 \\
(25.6)\end{array}$ & $\begin{array}{l}109 \\
(27.1)\end{array}$ & 1.00 & & 1.00 \\
\hline
\end{tabular}


In the present study, a mean DDS of $5.45 \pm 1.83$ SD was reported in Table 4. $60.9 \%$ of pregnant women had good dietary diversity practice and $39.1 \%$ pregnant women did not receive a minimum dietary diversity, which is better than a similar study conducted in Kenya, reported mean DDS 4.6 (36). But this mean DDS is lower as compared to literatures conducted in different countries, Another study in Kenya showed mean DDS of $6.84 \pm 1.46$ SD and $60.6 \%$ of pregnant women received minimum dietary diversity was reported (26). A Similar study done in Pakistan and South Africa among pregnant women, where a mean DDS of $6.17 \pm 0.99$ (39) and $6.70 \pm 2.22$ SD (40) was recorded, respectively. This result was also greater than study conducted in Bahir Dar town, North West Ethiopia; showed that only $39.3 \%$ of the pregnant women had good dietary practice and the rest $60.7 \%$ of pregnant women reported poor dietary practices (35). Another study done in Gondar, Ethiopia near to this study area reported $40.1 \%$ as a good dietary practice of pregnant women (21). Similarly, same study conducted in Gojam, North West, Ethiopia showed, that only $47 \%$ of women were received $\geq 4$ food group from 10 food groups (25). This difference is may be due to different cultural, educational and economic background and different study period for seasonal availability of different food groups.

In this study Table 4 , around $100 \%$ and $63.9 \%$ of the pregnant mothers had consumed cereals (grains, white roots and tubers, and plantain) and Pulses (beans, peas and lentils), respectively in the previous 24 hrs. Conversely, egg and the other fruit food group were least consumed food groups ( $8.9 \%$ and $21.8 \%$, respectively). Another study in Kenya showed that (99\%) pregnant women had eaten cereals, (93\%) vegetables and (92\%) milk and milk products, but foods of animal origin were minimally consumed only $4 \%$ (26). Similar finding is observed in south Achefer, West Gojjam, Ethiopia, a large proportion of women (98.3\%) relay on monotonous food group (25).

This study also showed that $31.3 \%$ of pregnant women avoid at least one food group from their meal. The reason for avoidance was either personal dislike or cultural beliefs that make the fetus, so big or causes maternal diarrhea. Similar study in Wollega, south west Ethiopia reported 35.8\% (27). Study in Bahir Dar town, North West Ethiopia; indicated that 203 (33\%) pregnant women avoid certain foods, of which $74.4 \%$ avoids food due to religious reason (35).

In regard to the association between dietary diversity and the selected maternal demographic factors (age, marital status, trimester of the pregnancy, occupation, and household size), this study did not find any statistically significant association. Similarly, findings were also documented in Kenya, except occupation those who reported being employed (salaried) had the highest odds ( 2.29 times) of attaining minimum dietary diversity as compared to the non-employed (26) and in Gondar, Ethiopia reported that no association (21). But, the study in Mirab Abaya, Southern, Ethiopia, reported that age and marital status had statistically significant association with pregnant women's dietary diversity (34).

Multivariable analysis showed that there was a statistically significant association $(p<0.05)$ between maternal educational status, family monthly income, second and third ANC visit and nutrition information with dietary diversity practices of pregnant mothers. 
Pregnant women with household income more than 5,000 ETB had dietary diversity practice almost 2.3 times than those households having a household income less than 2000 per month. And in Kenya those households with higher income had better chances of having diversified diets, those with an income of between Kenyan shilling (KSh) 20, 000 and KSh30, 000 were 2.01 times more likely to attain the minimum diversity as compared to those who had an income of less than 10, 000 (26). This association is the same to study in Gondar, Ethiopia, dietary practice during pregnancy among mothers who had monthly income of 1000-2000 was 2 times higher than those $<1000$ monthly income [AOR $=2.18,95 \%$ Cl: $(1.39,3.39)](21)$. The Slightly strong association also observed in Bahir Dar, Ethiopia, pregnant women earn more than 2000 ETB monthly were 3.1 times more likely to have good dietary practice than those earning less than $1000 \mathrm{ETB}[\mathrm{AOR}=3.12,95 \% \mathrm{Cl}, 91.743,5.586)](35)$

Pregnant women learned college and above had 2.3 times more dietary diversity practice than the illiterate mothers. Another related study also showed an association between women education and dietary diversity practice, in Kenya, study observed that those who had tertiary [AOR 2.93; $95 \% \mathrm{Cl} 1.40$, 8.63) and secondary education [AOR $2.78 ; 95 \% \mathrm{Cl}(1.06,5.32)$ ] had greater odds of achieving the minimum dietary diversity as compared to those who had never attended school (26). Which is supported by the study conducted in Gondar identified that educational status have a strong statistical association with dietary practices of mothers during pregnancy [AOR $=2.59,95 \% \mathrm{Cl}:(1.38,4.85)](21)$.

There is also a statistical association between nutrition information and dietary practices of mothers during pregnancy. Having nutrition information during pregnancy increases 2 times the dietary diversity practice of pregnant women than none informed ones. A Similar study showed strong association in Wollega, Western, Ethiopia, reported that Women who had information about nutrition during pregnancy had 6.3 more likely good nutrition practice than women who had no information during pregnancy [AOR $=6.26,95 \%$ Cl: (3.49-11.25)] (27) and in Gondar, Ethiopia, also there was a statistical association between nutrition information and dietary practices during pregnancy [AOR = 2.39, $\mathrm{Cl}$ : 1.44-3.97] (21). In Bahir Dar, Ethiopia, pregnant women who had nutrition information were 3.17 times more likely to have good dietary practices than their counterparts $[\mathrm{AOR}=3.17,95 \% \mathrm{Cl},(1.76,5.67)](35)$.

Pregnant women who were at second ANC visit $[\mathrm{AOR}=2.420,95 \% \mathrm{Cl}:(1.183,4.952)]$ and third ANC visit [AOR 2.300,95\% Cl: (1.014-5.213)] had more attaining minimum dietary diversity than who were at first visit. In Ghana showed that frequent ANC attendance were the only significant independent predictors of maternal dietary diversity (37). The association may be in three different reasons, first; pregnant women in the second and third visit had got enough health investigation, screening and nutritional advice during the first visit. Secondly, pregnant women at first visit had not information about dietary diversity and they might have hyperemesis which causes loss of appetite. Thirdly, pregnant women at the fourth visit assumed that eating protein diet at term leads the fetus big and not such important.

\section{Conclusions}


The mean dietary diversity scores among the pregnant mothers was 5.45 and $60.9 \%$ pregnant women had good dietary diversity practice.

All pregnant women, mostly rely on Cereals (Grains, white roots and tubers, and plantain), however, egg, other fruit and other vitamin A-rich fruits and vegetables were minimally eaten.

Factors like maternal educational status, family monthly income, second and third ANC visit and nutrition information were strongly associated with good dietary diversity practices of pregnant mothers.

\section{Abbreviations}

\section{Ethics approval and consent to participate:}

Bahir Dar University Ethical review committee wrote Ethical clearance to the Addis Ababa health bureau to give permission to conduct the research. And Then Ethical clearance was obtained from Ethical review committee of the Addis Ababa Health Bureau. Then the pregnant women from each selected health center were informed about the purpose of the study.

\section{Availability of data and materials:}

Questionnaire available as supplementary file

\section{Competing interests:}

The authors declare no Competing interests

\section{Funding:}

No fund for this research work

\section{Authors' Contributions:}

WT-wrote the first draft, data collection, analysis and interpretation

\section{Acknowledgements:}

Thank you for the respondents, and data collectors for their great role of successful data collection. We would like to express our heartfelt gratitude to Kolfe Keranyo sub city health office administration for their willingness, technical support and encouragement. We thank to Bahir Dar University for the opportunity 


\section{References}

1. Daniels CM. Dietary diversity as a measure of Women's diet quality in resource-poor areas: results from metropolitan Cebu, Philippines site. Washington: Food and Nutrition Technical Assistance II Project (FANTA-2);2009.

2. Kennedy, G. Evaluation of dietary diversity scores for assessment of micronutrient intake and food security in developing countries. Wageningen University, 2009.

3. Drimie, S., Faber, M., Vearey, J., \& Nunez, L. Dietary diversity of formal and informal residents in Johannesburg, South Africa, 2013; 13(1): 911.

4. Ey, C. E., Zalilah, M. S., Ys, C. Y., \& Norhasmah, S. Dietary diversity is associated with the nutritional status of Orang Asli children in Krau Wildlife Reserve, Pahang. Malaysian Journal of Nutrition, 2012; 18(1):1-13.

5. Arimond, M., Wiesmann, D., Becquey, E., Carriquiry, A., Daniels, M.C., Deitchler, M., Fanou- Fogny, N., Joseph, M.L., Kennedy, G., Martin-Prével, Y. \& Torheim, L.E. Simple food group diversity indicators predict the micronutrient adequacy of women's diets in 5 diverse, resource-poor settings. J Nutr.2010; 140(11): 2059S-69S.

6. Arimond, M. and Ruel, M. (2002), "Summary indicators of infant and child feeding practices: An example of the Ethiopia Demographic and Health Survey 2000", Food Consumption and Nutrition Division Discussion Paper, Washington, D.C.: International Food Policy Research Institute.

7. World Health Organization,(2012). Nutrition of women in the preconception period, during pregnancy and the breastfeeding period Report by the Secretariat: sixty-fifth world health assembly A65/12; Provisional agenda item 13.3.

8. Maternal Nutrition during Pregnancy and Lactation is a joint publication of LINKAGES:

Breastfeeding, LAM, Related Complementary Feeding, and Maternal Nutrition Program and the Child Survival Collaborations and Resources (CORE) Nutrition Working Group. August, 2014

9. Taddese Alemu. Dietary practices of pregnant women and its associations with maternal and perinatal outcomes in rural Central Ethiopia,2016;8:48

10. Allen, L., Multiple micronutrients in pregnancy and lactation: an overview, American Journal of Clinical Nutrition, 2005, 81(5), 1206S-12S.

11. Ruel, M.T. Operationalising dietary diversity: a review of measurement issues and research priorities, Journal of Nutrition, 2003; 133 (11 Suppl. 2): 3911-26.

12. Torheim, L.E., et al., Women in resource-poor settings are at risk of inadequate intakes of multiple micronutrients, Journal of Nutrition, 2010,

13. VArimond, M., Wiesmann, D., Becquey, E., Carriquiry, A., Daniels, M., Deitchler, M., Fanou, N., Ferguson, E., Joseph, M., Kennedy, G., Martin-Prével, Y., Torheim, L.E., Dietary diversity as a measure of the micronutrient adequacy of women's diets in resource-poor areas: summary of results from five sites, Food and Nutrition Technical Assistance FANTA-2 Bridge and Food Health International, FHI 360, 
14. Custodio E., Kayitakire F. And Thomas A.C.(2015).; Exploring the new indicator minimum dietary diversity-women. Results from Burkina Faso; EUR 27717; doi:10.2788/86023; FAO. Guidelines for measuring household and individual dietary diversity. Rome: Food and Agriculture Organization of the United Nations; 2016.

15. FAO Summary Report, Meeting to reach consensus on a global dietary diversity indicator for women, Washington, D.C., 2014;7:15-16.

16. Abdel-Razeq, S. \& Buhimschi, I. Interpretation of Amniotic Fluid White Blood Cell Count in "Bloody Tap" Amniocenteses in Women With Symptoms of Preterm Labor. Obstet Gynecol, 201;116;344354.

17. Bain, L.E. 2013. Malnutrition in Sub-Saharan Africa: burden, causes and prospects. The Pan African medical journal, 15, p.120. World Health Organization, 2013. Trends in Maternal Mortality : 1990 to 2013.

18. WHO, UNICEF, UNFPA, The World Bank and the United Nations Population Division.Trends in maternal mortality:1990 to 2015 Geneva:World health organization,2015.

19. Imamura, F. et al. Dietary quality among men and women in 187 countries in 1990 and 2010: The Lancet Global Health 2015;3(3):132-142.

20. Global nutrition report ,2016

21. Mekonnen Sisay., Endalamaw Memgesha. Dietary Practice and Associated Factors among Pregnant Women in Gondar Town North West, Ethiopia, 2014. International Journal of Nutrition and Food Sciences, 2015;4(6),: 707-712

22. Kuche Desalegn, Singh Pragya, Moges Debebe. Dietary practices and associated factors among pregnant women in Wondo genet district, southern Ethiopia: A cross-sectional study, 2015;4(5):270275.

23. USAID, ENGINE and save the children ;maternal diet and nutrition practices and their determinants engine: Empowering New Generations to Improve Nutrition and Economic opportunities A project supported by the Feed the Future and Global Health Initiatives A report on formative research findings and recommendations for social and behavior change communication programming in the Amhara, Oromia, SNNP and Tigray regions of Ethiopia; April 2014

24. Taddese A .Melaku U.and Kaleab B; Dietary diversity during pregnancy is associated with reduced risk of maternal anemia, preterm delivery, and low birth weight in a prospective cohort study in rural Ethiopia. AJCN. First published ahead of print May 11, 2016;10:115.116.

25. Abel Ahmed.2014.; Assessment of Dietary diversity among pregnant and lactating women and 6 to 23 months age children, in rural areas of western Gojjam, Amhara Region

26. Willy K, Judith K, Peter C. Dietary diversity, nutrient intake and nutritional status among pregnant women in Laikipia county, Kenya, 2016; 6(4):378-385.

27. Gemeda Daba, et al. Assessment of Nutritional Practices of Pregnant Mothers on Maternal Nutrition and Associated Factors in Guto Gida Woreda, East Wollega Zone, Ethiopia, 2013; 2(3): 105-113 
28. Central Statistical Agency (CSA) [Ethiopia] and ICF. 2016. Ethiopia Demographic and Health Survey 2016: Key Indicators Report. Addis Ababa, Ethiopia, and Rockville, Maryland, USA. CSA and ICF.

29. FAO, 2013. FAO Statistical Yearbook 2013: World food and agriculture. FAO Statistical Yearbook 2013: World food and agriculture, pp.1-307.

30. Kassebaum, N.J. et al., 2014. A systematic analysis of global anemia burden from 1990 to 2010;123(5):615-624.

31. Daniels, Melissa C. (2009). Dietary Diversity as a Measure of the Micronutrient Adequacy of Women's Diets: Results from Metropolitan Cebu, Philippines Site. Washington, DC: Food and Nutrition Technical Assistance II Project, FHI 360.

32. Alemu Taddese \& Umeta M. Reproductive and Obstetric Factors Are Key Predictors of Maternal Anemia during Pregnancy in Ethiopia : Evidence from Demographic and Health Survey (2011). 2015: pp.1-10.

33. Fatima A, Inayat T, Shahzad A. Assessment of dietary diversity and nutritional status of pregnant women in islamabad, pakistan, 2014; 26(4) :48.

34. Direslgne Misiker. Begosew Misker. Gistane Ayele.; House hold dietary diversity and associated factors in Mirab Abaya wereda Southern Ethiopia: Diversity and Equality in Health and Care, 2016; 13(4): 293-296

35. Amanuel N. and Tona Z.: Dietary practices and associated factors during pregnancy in northwestern Ethiopia, 2018; 18:183

36. Lydiah M. Waswa. Improving dietary diversity and nutritional health of women and children under two years through increased utilization of local agrobiodiversity and enhanced nutrition knowledge in Kenya, 2016.

37. Mahama S. Maternal Dietary Diversity and Infant Outcome of Pregnant Women in Northern Ghana. International Journal of Child Health and Nutrition, 2012;1: 148-156

38. Kolfe Keranyo sub city health office report,2017

39. Ali F, Thaver I, Khan SA. Assessment of dietary diversity and nutritional status of pregnant women in Islamabad, Pakistan, 2014;26(4):506-9.

40. Acham H, Oldewage-Theron W, Egal AA. Dietary diversity, micronutrient intake and their variation among black women in informal settlements in South Africa: a cross-sectional study. Intern J Nutr Metab. 2012;4:24-39.

\section{Supplementary Files}

This is a list of supplementary files associated with this preprint. Click to download.

- supplementaryfileQuestionnair.pdf 